\title{
Differential changes in Neuregulin-1 signaling in major brain regions in a lipopolysaccharide-induced neuroinflammation mouse model
}

\author{
ZHAI YANG $^{1}$, QIONG JIANG ${ }^{1}$, SHUANG-XI CHEN ${ }^{1}$, CHENG-LIANG HU ${ }^{1}$, HUI-FAN SHEN ${ }^{1}$, \\ PEI-ZHI HUANG ${ }^{1}$, JUN-PING XU ${ }^{1}$, JIN-PING MEI ${ }^{2}$, BEN-PING ZHANG ${ }^{3}$ and WEI-JIANG ZHAO ${ }^{1}$ \\ ${ }^{1}$ Center for Neuroscience, Shantou University Medical College, Shantou, Guangdong 515041; \\ ${ }^{2}$ Graduate School, Tianjin University of Traditional Chinese Medicine, Tianjin 300193; \\ ${ }^{3}$ Department of Neurology, The 2nd Affiliated Hospital, Harbin Medical University, Harbin, Heilongjiang 150086, P.R. China
}

Received July 9, 2015; Accepted May 10, 2016

DOI: $10.3892 / \mathrm{mmr} .2016 .5325$

\begin{abstract}
Neuregulin $1(\mathrm{Nrg} 1)$ is involved in multiple biological processes in the nervous system. The present study investigated changes in Nrg1 signaling in the major brain regions of mice subjected to lipopolysaccharide (LPS)-induced neuroinflammation. At $24 \mathrm{~h}$ post-intraperitoneal injection of LPS, mouse brain tissues, including tissues from the cortex, striatum, hippocampus and hypothalamus, were collected. Reverse transcription-polymerase chain reaction was used to determine the expression of $\mathrm{Nrg} 1$ and its receptors, Neu and ErbB4, at the mRNA level. Western blotting was performed to determine the levels of these proteins and the protein levels of phosphorylated extracellular signal-regulated kinases (Erk)1/2 and Akt1. Immunohistochemical staining was utilized to detect the levels of pNeu and pErbB4 in these regions. LPS successfully induced sites of neuroinflammation in these regions, in which changes in $\mathrm{Nrg} 1, \mathrm{Neu}$ and ErbB4 at the mRNA and protein levels were identified compared with controls. LPS induced a reduction in pNeu and pErbB4 in the striatum and hypothalamus, although marginally increased pErbB4 levels were found in the hippocampus. LPS increased the overall phosphorylation of Src but this effect was reduced in the hypothalamus. Moreover, increased phosphorylation of Akt1 was found in the striatum and hippocampus. These data suggest diverse roles for $\mathrm{Nrg} 1$ signaling in these regions during the process of neuroinflammation.
\end{abstract}

Correspondence to: Dr Wei-Jiang Zhao, Center for Neuroscience, Shantou University Medical College, 22 Xinling Road, Shantou, Guangdong 515041, P.R. China

E-mail: neuromancn@aliyun.com

Key words: neuroinflammation, neuregulin-1, ErbB receptors, lipopolysaccharide

\section{Introduction}

Neuregulin $1(\mathrm{Nrg} 1)$ is a member of the epidermal growth factor family and functions through the activation of the tyrosine kinase domain of ErbB receptors (1). The bioactivity of $\mathrm{Nrg} 1$ is primarily mediated via homodimers consisting of its cognate receptor ErbB4 (2) or via heterodimeric complexes of ErbB3/Neu and ErbB4/Neu (3). These receptors, including Neu and ErbB4, have a high affinity for $\mathrm{Nrg} 1$ and contain an active tyrosine kinase domain (4). The interaction between ligands and receptors regulates a wide spectrum of biological processes via the initiation of a complicated cascade of intracellular signaling pathways, in which extracellular signal-regulated kinases (Erk), Akt, mitogen-activated protein kinase (MAPK), PI $3 \gamma$, protein kinase C (PKC) and Jak-STAT are involved (5-8). Moreover, the activation of these signaling pathways may lead to cell cycle arrest, cell proliferation, differentiation, tumorigenic development and anti-apoptotic processes $(3,9,10)$. A previous study demonstrated that the Nrg1-ErbB signaling pathway is essential in organ development, cell differentiation and tumorigenesis (7).

Expression and functions of $\mathrm{Nrg} 1$ have also been systematically described in the nervous system, particularly in the spinal cord, cortex and hippocampus. Moreover, recent data suggest that Nrg1-ErbB4 signaling is key in the pathogenesis of a diverse range of neurodegenerative and neurological diseases, including Alzheimer's disease (11,12), multiple sclerosis (13), schizophrenia (14), neurospongioma (15) and brain damage (5). Perturbed Nrg1 signaling in these diseases extends our understanding of the biological functions of $\mathrm{Nrg} 1$.

Neuroinflammation is essential in diseases affecting the central nervous system (CNS). Neuronal apoptosis occurs in response to multiple cytokines, chemokines and toxic factors secreted by glial cells during this process (16). Inflammatory signals, such as prostaglandins, proinflammatory cytokines or lipopolysaccharide (LPS), can cross the intact or ruptured blood-brain barrier (BBB) of the CNS (17), and controlled and balanced inflammation contribute to the repair of damaged tissues following brain injury (18).

Although multiple factors have been determined to be associated with the neuroinflammatory process, the involvement 
of Nrg1-ErbB signaling in this condition remains largely unknown. Nrg1, like other specific members of the cytokine family, such as interleukin-1 and epidermal growth factor (EGF), was affected following brain infection and injury; thus, $\mathrm{Nrg} 1$ is hypothesized to partially contribute to the development of schizophrenia (19). Nrg1 mRNA and intracellular protein levels increased in response to the duration of LPS exposure in human umbilical venous endothelial cells, supporting its potential role as a systemic endogenous inhibitor of perinatal inflammatory brain damage during fetal development (20).

It was hypothesized that inflammation can affect the expression of $\mathrm{Nrg} 1$ and result in intracellular signaling changes, thus contributing to the pathology of neuroinflammation-based neurodegenerative diseases. LPS is a component of the outer cell wall of Gram-negative bacteria, and it has been widely used to induce inflammation in the brain $(11,21)$. Therefore, the effects of LPS-induced neuroinflammation on the expression of $\mathrm{Nrg} 1$ and its related cell signaling molecules were analyzed in several major brain structures in vivo using a mouse model treated with intraperitoneal injection of LPS.

It was observed that LPS induced differential changes in Nrg1 and its receptors Neu and ErbB4 in the cortex, striatum, hippocampus and hypothalamus. Notably, a profound reduction of $\mathrm{Nrg} 1$ expression was found in the hypothalamus and striatum, suggesting that the Nrg1 signaling in these locations is more prone to be influenced by LPS-induced neuroinflammation. These findings may provide greater insight into the function of Nrg1 in inflammation-related neuronal diseases, including AD, PD and SCI, and may further aid in the development of novel clinical therapies.

\section{Materials and methods}

Animals. Eleven female C57BL/6 mice (age, 3 months; weight, $25 \mathrm{~g}$ ) were purchased from the Guangdong Medical Laboratory Animal Center (Guangzhou, China) and were maintained at $25^{\circ} \mathrm{C}$ under a 12-h dark/light cycle, with access to food and water ad libitum. All experimental procedures conducted on animals were approved by the Animal Ethics Committees of Shantou University Medical College (Shantou, China) and the authorities of Guangdong Province.

LPS treatment. A total of $1.0 \mathrm{mg}$ LPS (Sigma-Aldrich Israel, Ltd., Rehovot, Israel) was dissolved in $10 \mathrm{ml}$ normal saline ( $\mathrm{pH}$ 7.4), such that the final concentration of LPS solution was $0.01 \%$. Six mice were intraperitoneally injected with LPS at a dose of $1.0 \mathrm{mg} / \mathrm{kg}(10 \mathrm{ml} / \mathrm{kg})$, and 5 mice in the control group were injected with normal saline at $10 \mathrm{ml} / \mathrm{kg}$.

Tissue preparation. Mice were then sacrificed by decapitation $24 \mathrm{~h}$ after LPS or saline injection. For morphological studies, 2 mice from each group were subjected to intracardiac perfusion of phosphate-buffered saline-buffered paraformaldehyde for fixation. For molecular studies, seven brains, three from the normal saline-treated mice and four from LPS-treated mice, were collected. The right and left hemisphere from each brain was separated. Moreover, the frontoparietal cortex, hippocampus, striatum and hypothalamus from each side were dissected and stored at $-80^{\circ} \mathrm{C}$ for either reverse transcription-polymerase chain reaction (RT-PCR) or western blot analysis (22).
RT-PCR analysis. Total RNA from brain tissue was extracted using the DNAiso Reagent (Tiangen Biotech (Beijing) Co., Ltd., Beijing, China) according to the manufacturer's protocol. Reverse transcription was performed using StarScript II First-strand cDNA Synthesis mix (Gene-star Biosolutions Co., Ltd., Beijing, China), and RT-PCR was performed using 2X Taq PCR StarMix (Genstar Solutions). Sequences of primers are listed in Table I. PCR amplification was conducted with an initial denaturing step at $94^{\circ} \mathrm{C}$ for $2 \mathrm{~min}$, then 35 cycles at $94^{\circ} \mathrm{C}$ for $30 \mathrm{sec}$, at $60^{\circ} \mathrm{C}$ for $30 \mathrm{sec}$, and at $72^{\circ} \mathrm{C}$ for $30 \mathrm{sec}$, and a further extension at $72^{\circ} \mathrm{C}$ for $10 \mathrm{~min}$. For glyceraldehyde 3 -phosphate dehydrogenase (GAPDH) cDNA amplification, 28 reaction cycles were employed. Then, $5 \mu 1$ of the PCR products were used to perform gel electrophoresis using a $2.0 \%$ agarose gel (GeneChoice, Inc., Frederick, MD, USA) containing Gelred (1:10,000; Biotium, Inc., Hayward, CA, USA). The bands were identified under ultraviolet light.

Western blot analysis. For western blot analysis, tissue was dissolved in $200 \mu 1$ radioimmunoprecipitation buffer containing PMSF (1\%) (Solarbio Biotech Corp, Beijing, China) and homogenized using a motor-driven micro tissue grinder (Kimble Chase, Vineland, NJ, USA). The supernatants were collected following centrifugation at $14,000 \times \mathrm{g}$ for $15 \mathrm{~min}$ at $4^{\circ} \mathrm{C}$. Protein concentrations were determined by the bicinchoninic acid assay (Solarbio Biotech Corp). Equivalent quantities $(20 \mu \mathrm{g})$ of tissue lysates were heated at $95^{\circ} \mathrm{C}$ in $20 \%$ sample loading buffer consisting of $0.125 \mathrm{~mol} / 1$ Tris-HCl, $\mathrm{pH} \mathrm{1.8;20 \%}$ glycerol, $10 \%$ sodium dodecyl sulfate, $0.1 \%$ bromophenol blue and $5 \% \beta$-mercaptoethanol, and were then resolved using $10 \%$ sodium dodecyl sulfate-polyacrylamide gel electrophoresis and electroblotted onto a polyvinylidene difluoride membrane (Millipore, Billerica, MA, USA). Non-specific protein-binding sites were blocked with $5 \%$ bovine serum albumin (Amresco, LLC, Solon, OH, USA) or non-fat milk diluted in Tris-buffered saline buffer containing $0.1 \%$ Tween-20 (TBST, pH 7.4). The membranes were incubated with the following anti-mouse primary antibodies: Polyclonal rabbit p-ErbB-4 (Tyr 1056; 1:500; \#sc-33040); polyclonal rabbit ErbB-4 (C-18; 1:500; \#sc-283); polyclonal mouse p-ErbB-2/p-Neu (7F8; 1:500; \#sc-81508); monoclonal mouse Neu (3B5; 1:500; \#sc-33684); polyclonal rabbit p-c-Src (Tyr 419; 1:500; \#sc-101802); monoclonal mouse Src-1 (1135/H4; 1:500; \#sc-32789); monoclonal mouse anti-p-Akt1/2/3 (11E6; 1:1,000; \#sc-81433); monoclonal mouse Akt1 (G-5; 1:1,000; \#sc-55523); monoclonal mouse p-Erk (E-4; 1:1,000; \#sc-7383); monoclonal mouse Erk1/2 (MK1; 1:1,000; \#sc-135900); monoclonal mouse GAPDH (G-9; 1:1,000; \#sc-3650620) (all 1:1,000 Santa Cruz Biotechnology, Inc., Dallas, TX, USA) and monoclonal mouse Nrg1 Ab-1 (7D5; 1:500; MS-272-P1; LabVision; Thermo Fisher Scientific, Inc., Waltham, MA, USA) overnight at $4^{\circ} \mathrm{C}$. After 3 washes for $5 \mathrm{~min}$ each, horseradish peroxidase-conjugated goat anti-mouse (\#BA1051) and rabbit anti-goat (\#BA1055) secondary antibodies (1:1,000; Wuhan Boster Biological Technology, Ltd., Wuhan, China) diluted in 3\% non-fat milk in TBST were applied, followed by 3 washes with TBST for $5 \mathrm{~min}$ each at room temperature. The antigens were visualized using an enhanced chemiluminescence (ECL) solution (Beyotime Institute of Biotechnology, Haimen, China). The signal intensity was quantified using Image $\mathbf{J}$ software, 
Table I. Sequences of primers for reverse transcription-polymerase chain reaction.

\begin{tabular}{|c|c|c|c|c|c|}
\hline Gene & Domain & Primers & Accession no. & $\begin{array}{c}\text { Annealing } \\
\text { temperature }\left({ }^{\circ} \mathrm{C}\right)\end{array}$ & $\begin{array}{l}\text { Expected } \\
\text { length (bp) }\end{array}$ \\
\hline ErbB4 & $\begin{array}{l}5^{\prime} \text { terminus } \\
3^{\prime} \text { terminus }\end{array}$ & $\begin{array}{l}\text { 5'-GCCAAAAATGAAGCTGGCGA-3' } \\
\text { 5'-TTGTGCTCGATGCTGGTGAT-3' }\end{array}$ & NM_010154.1 & 60 & 219 \\
\hline $\mathrm{Neu}$ & $\begin{array}{l}5 \text { ' terminus } \\
3^{\prime} \text { terminus }\end{array}$ & $\begin{array}{l}\text { 5'-TAGCTGGGCATTCACCCTAC-3' } \\
\text { 5'-AGGGCATAAGCTGTGTCACC-3' }\end{array}$ & ВС053078.1 & 55 & 358 \\
\hline $\operatorname{Nrg} 1$ & $\begin{array}{l}5 ' \text { terminus } \\
3^{\prime} \text { terminus }\end{array}$ & $\begin{array}{l}\text { 5'-GTCTCAGAGGGTGCCTCAAC-3' } \\
\text { 5'-GTTCTTCCGGGTGGGTACTG-3' }\end{array}$ & NM_178591.2 & 60 & $332 / 230$ \\
\hline GAPDH & $\begin{array}{l}5 \text { ' terminus } \\
3^{\prime} \text { terminus }\end{array}$ & $\begin{array}{l}\text { 5'-GTGGAGTCATACTGGAACATGTAG-3' } \\
\text { 5'-AATGGTGAAGGTCGGTGTG-3' }\end{array}$ & & 60 & 150 \\
\hline
\end{tabular}

Nrg1, neuregulin 1; GAPDH, glyceraldehyde 3-phosphate dehydrogenase.

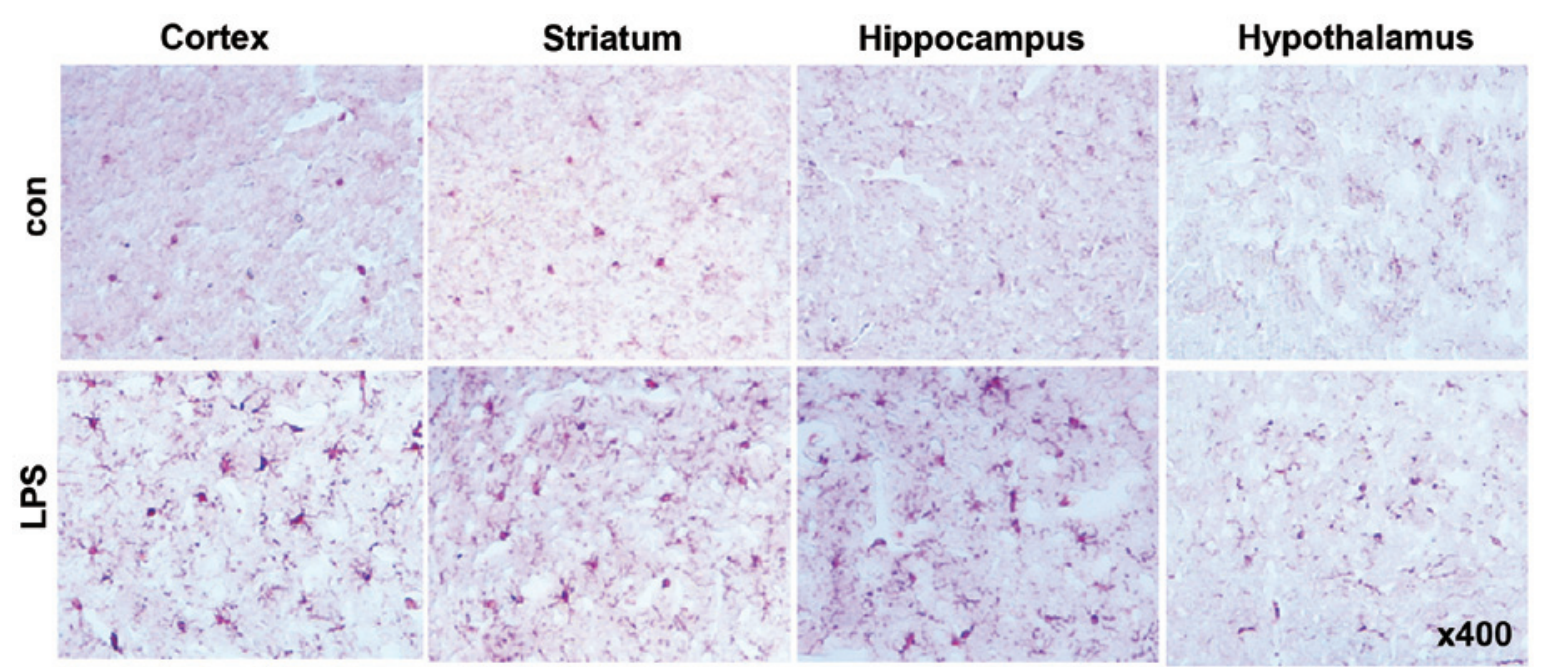

Figure 1. Systemic LPS injection induced neuroinflammation in major brain regions. Immunohistochemical staining demonstrated a wide distribution of Iba-1-positive activated microglia in the cortex, striatum and hippocampus. By contrast, the number of activated microglia was limited in the hypothalamus. LPS, lipopolysaccharide.

version 1.48 (rsb.info.nih.gov/ij/) as the average densitometry multiplied by the area (measured as the number of pixels).

Immunohistochemical staining. Mice were perfused with a $4 \%$ paraformaldehyde solution followed by decapitation and then cryoprotected in $20 \%$ sucrose. Brain sections $(8 \mu \mathrm{m}$ thick) were prepared using a cryostat microtome (Leica CM1860, Leica Biosystems, Germany). Antigen retrieval was performed using 10-mM citrate buffer $(\mathrm{pH} \mathrm{6.0)}$ ) for $40 \mathrm{~min}$ at $99^{\circ} \mathrm{C}$. Then, the tissue sections were incubated in $3 \% \mathrm{H}_{2} \mathrm{O}_{2}$ to clear endogenous peroxidase and were then saturated with $10 \%$ normal goat serum for $10 \mathrm{~min}$. Next, sections were incubated with the following primary antibodies: Rabbit polyclonal anti-pNeu and pErbB4 antibodies (1:100; Santa Cruz Biotechnology, Inc.). After being washed in PBS 3 times for $5 \mathrm{~min}$ each, the biotinylated secondary antibody and the streptavidin-peroxidase conjugate were applied. The enzyme activity was developed using an AEC kit (ZLI-9036; ZSGB Biotechnology Co., Ltd., Beijing, China). the antigen-antibody complexes were visualized using the AEC method, according to the manufacturer's protocols.
Statistical analysis. Statistical analyses were performed with SPSS17.0 (SPSS software Inc., Chicago, IL, USA). Data were analyzed using Student's t-test for independent samples. $\mathrm{P}<0.05$ was considered to indicate a statistically significant difference.

\section{Results}

Neuroinflammatory response to LPS administration in major mouse brain regions. Intraperitoneal administration of LPS induced an apparent increase in the number of activated microglial cells positive for Iba-1 in the cortex, striatum, hippocampus and hypothalamus (Fig. 1), indicating the successful induction of neuroinflammation in our model.

Determination of $\mathrm{Nrgl}$, Neu and ErbB4 expression in different brain regions in response to LPS. RT-PCR was used to investigate the expression changes of Nrg1, Neu and ErbB4 at the mRNA level in major brain regions in response to LPS administration for $24 \mathrm{~h}$. It was demonstrated that LPS induced an apparent increase in the Neu mRNA level in the cortex, striatum and hippocampus, but a profound reduction 
A

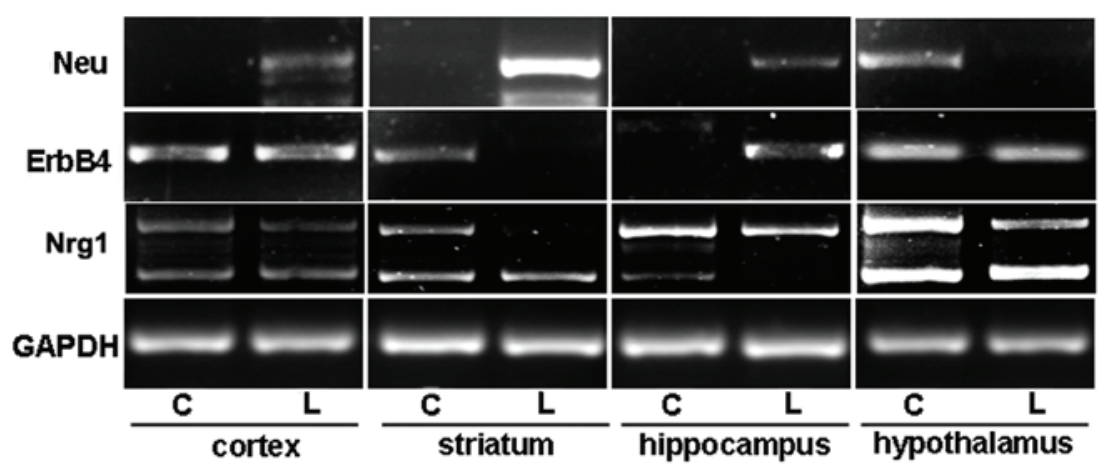

B

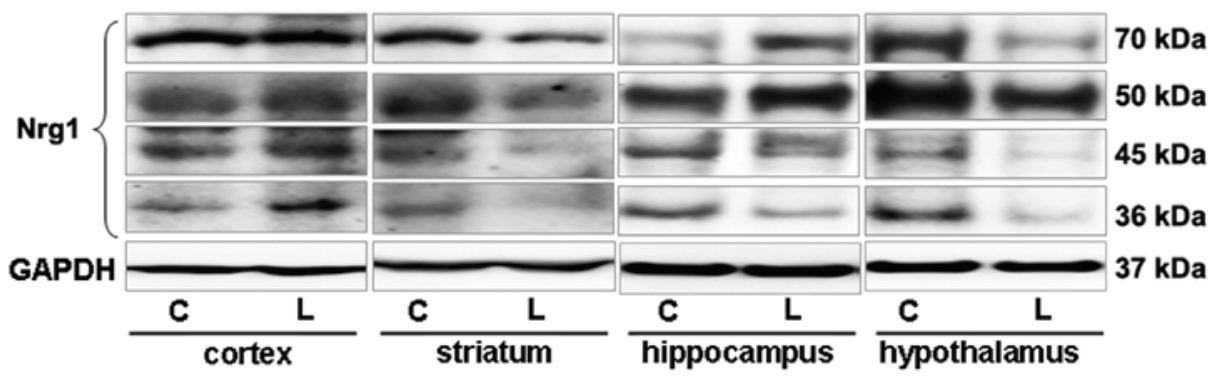

C

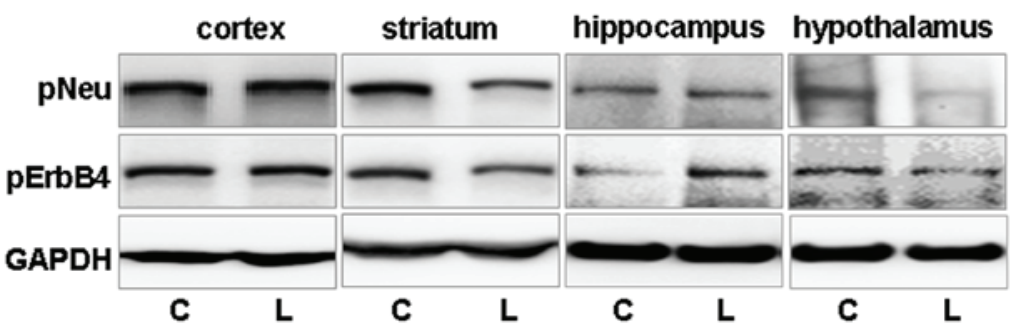

D

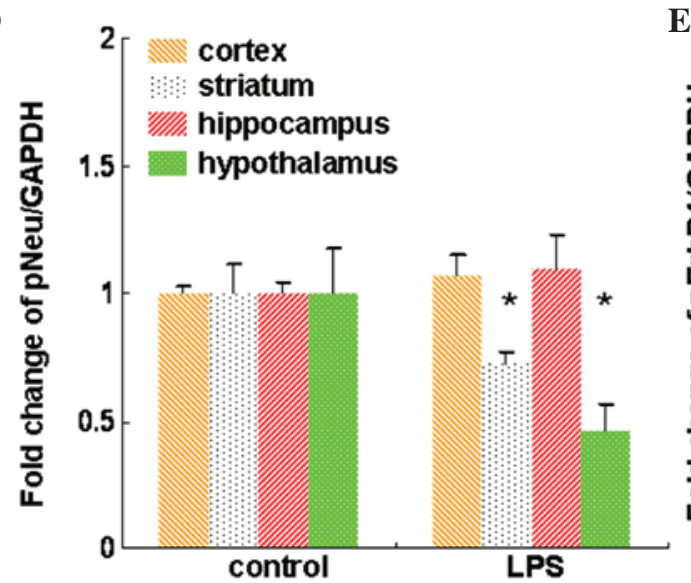

$\mathbf{E}$

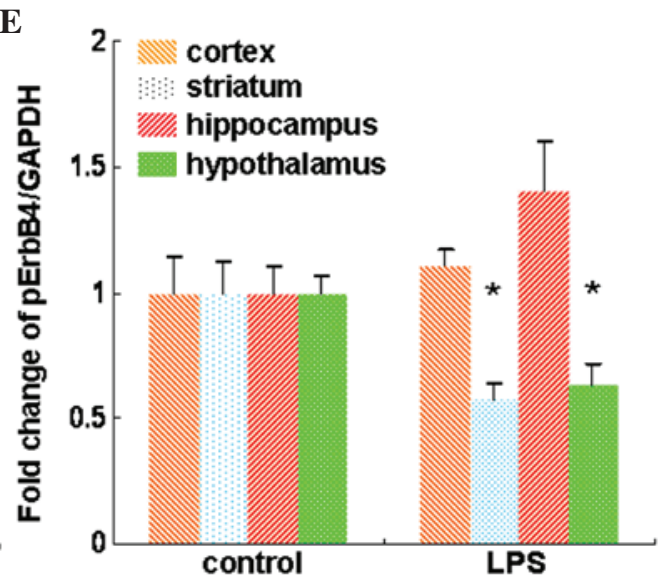

Figure 2. Evaluation of the effects of LPS on Nrg1 expression and Neu and ErbB4 expression and activation in mouse cortex, striatum, hippocampus and hypothalamus. (A) Reverse transcription-polymerase chain reaction analysis of the influence of LPS on the mRNA levels of Nrg1, Neu and ErbB4. (B) Western blot analysis of the effect of LPS on the protein levels of multiple isoforms of Nrg1. (C) Western blot analysis of the effect of LPS on the phosphorylation-induced activation of Neu and ErbB4. Quantification of the (D) Neu and (E) ErbB4 westernblot results. Independent Student's t-test was applied. ${ }^{*}<<0.05$ vs. the control group (control group, n=3; LPS group, n=4). LPS, lipopolysaccharide; Nrg1, neuregulin-1; C, control group; L, LPS group; GAPDH, glyceraldehyde 3-phosphate dehydrogenase; p-, phosphorylated.

in the Neu mRNA level was observed in the hypothalamus (Fig. 2A). LPS showed no effect on the mRNA levels of ErbB4 in the cortex and hypothalamus (Fig. 2A). However, the mRNA levels of ErbB4 were reduced in the striatum but were increased in the hippocampus in the LPS-treated mice compared with that of the controls (Fig. 2A). In addition, LPS reduced the mRNA levels of type I Nrg1 in the striatum and hypothalamus (Fig. 2A). In accordance with these findings, in these 2 regions reduced protein levels of Nrg1 were observed, the molecular weights of which were 70, 50, 45 and $36 \mathrm{kDa}$. By contrast, the mRNA level of type II Nrg1 was reduced in the hippocampus, which also showed reduced 45 and $36 \mathrm{kDa}$ Nrg1 protein levels (Fig. 2B). Notably, the LPS-treated mice showed no apparent changes in the mRNA levels of both types of Nrg1 


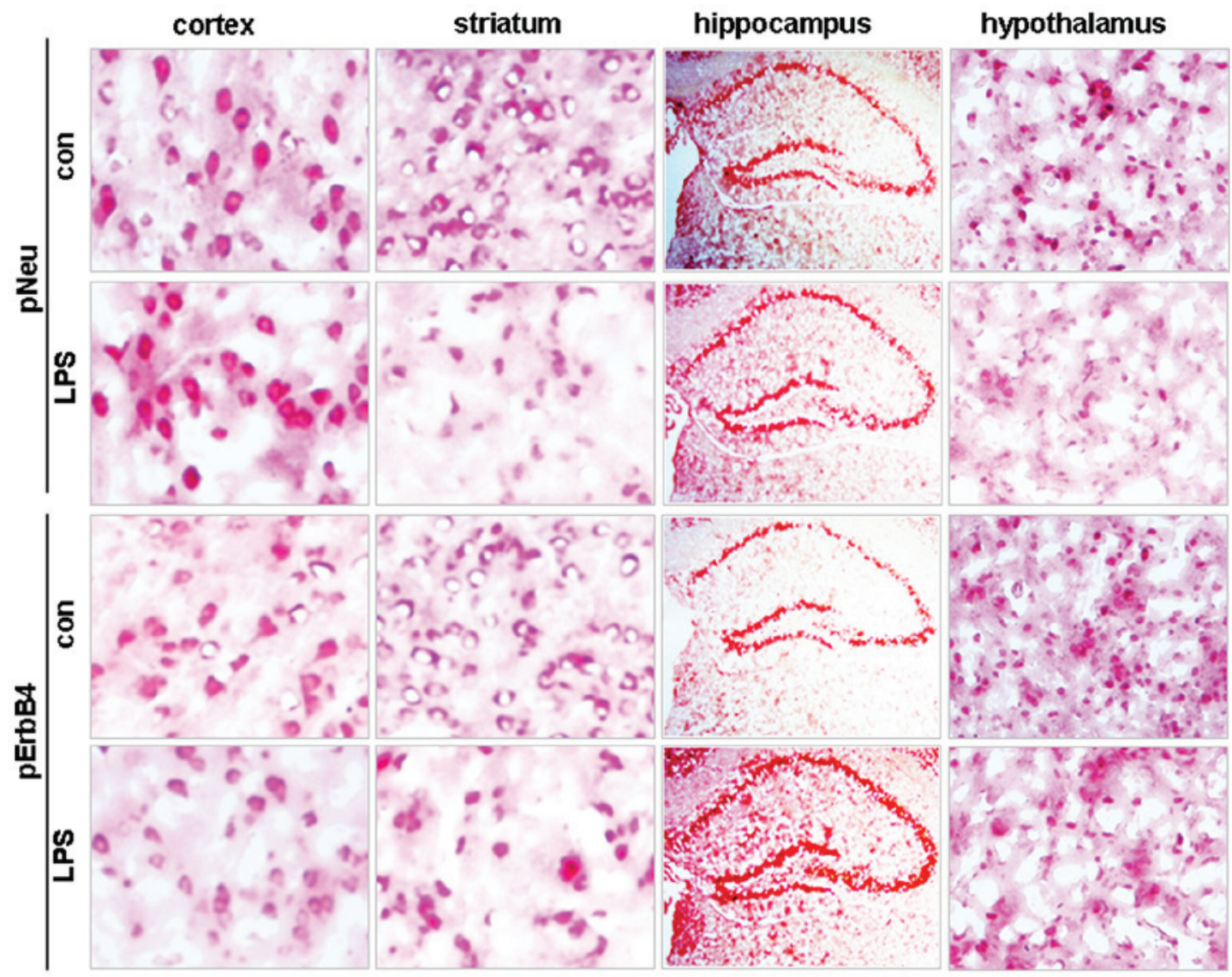

Figure 3. Immunohistochemical staining of pNeu and pErbB4 in the cortex, striatum, hippocampus and hypothalamus in mice treated with either saline (con) or LPS. Original magnification, x400 for cortex, striatum and hypothalamus; x100 for hippocampus. LPS, lipopolysaccharide; p-, phosphorylated.

in the cortex compared with the vehicle control mice (Fig. 2B). This was further confirmed by western blot analysis, which revealed no profound changes in the different $\mathrm{Nrg} 1$ isoforms at the protein level (Fig. 2B).

The effect of LPS on Neu and ErbB4 phosphorylation was then investigated in major brain regions. As shown in Fig. 2C and D, administration of LPS showed no apparent effect on the phosphorylation of Neu and ErbB4 in the cortex ( $\mathrm{P}>0.05$ vs. the vehicle control); however, it induced a significant reduction in the phosphorylation of molecules in the striatum and hypothalamus ( $\mathrm{P}<0.05$ vs. the vehicle control; Fig. $2 \mathrm{C}$ and $\mathrm{D})$. In the hippocampus, LPS showed no effect on pNeu level, but it increased the pErbB4 level (Fig. 2C-E).

Effect of LPS on the phosphorylation-induced activation of $\mathrm{Neu}$ and ErbB4 in major brain regions in mice. In accordance with the western blot data, immunohistochemical staining demonstrated no changes in either pNeu or pErbB4 levels in cortical brain tissue, but it reduced the stained signals for the two molecules in the striatum and hypothalamus (Fig. 3). None of the hippocampal areas, including the CA1, CA2 and CA3 zones and the dentate gyrus, showed changes in pNeu levels, whereas increased pErbB4 levels were observed in these areas in LPS-treated mice compared with control (Fig. 3).

Western blot analysis of the effects of LPS on signaling pathways in different parts of the brain. To gain additional insight into the influence of LPS on the downstream signaling pathways of Nrg1, the phosphorylation levels of Src, Akt1 and Erk were measured using western blot analysis (Fig. 4). The phosphorylation of c-Src was significantly upregulated in the cortical tissue $(\mathrm{P}<0.05$ vs. the vehicle control). By contrast, it was downregulated in the hypothalamus $(\mathrm{P}<0.01$ vs. the vehicle control) (Fig. 4A and B). In addition, the Akt1 phosphorylation level, as indicated by the pAkt1/Akt1 ratio, was significantly increased in the striatum $(\mathrm{P}<0.05$ vs. the vehicle control), with no significant changes identified in the cortex and hypothalamus. The hippocampus also showed an increased average pAkt1/Akt1 ratio, although no significant difference was found when compared with the control mice (Fig. 4A and C). As indexed by pErk/Erk ratio, LPS resulted in marginally reduced Erk phosphorylation in the cortex but increased it in the striatum, although no significance was found when compared with the vehicle controls. No obvious changes in Erk phosphorylation were observed in either the hippocampus or hypothalamus (Fig. 4A and D).

\section{Discussion}

Traditionally, transforming growth factor $\alpha$-transactivated ErbB1/epidermal growth factor receptor is required for the LPS response, and neuregulins are required to transactivate ErbB4 during the acid-stress response (23). Stability enhancement of neuregulin receptor degradation protein-1 inhibits the production of proinflammatory cytokines in macrophages triggered by toll-like receptors. This process may also reduce the production of LPS-induced proinflammatory mediators, such as inducible 
A
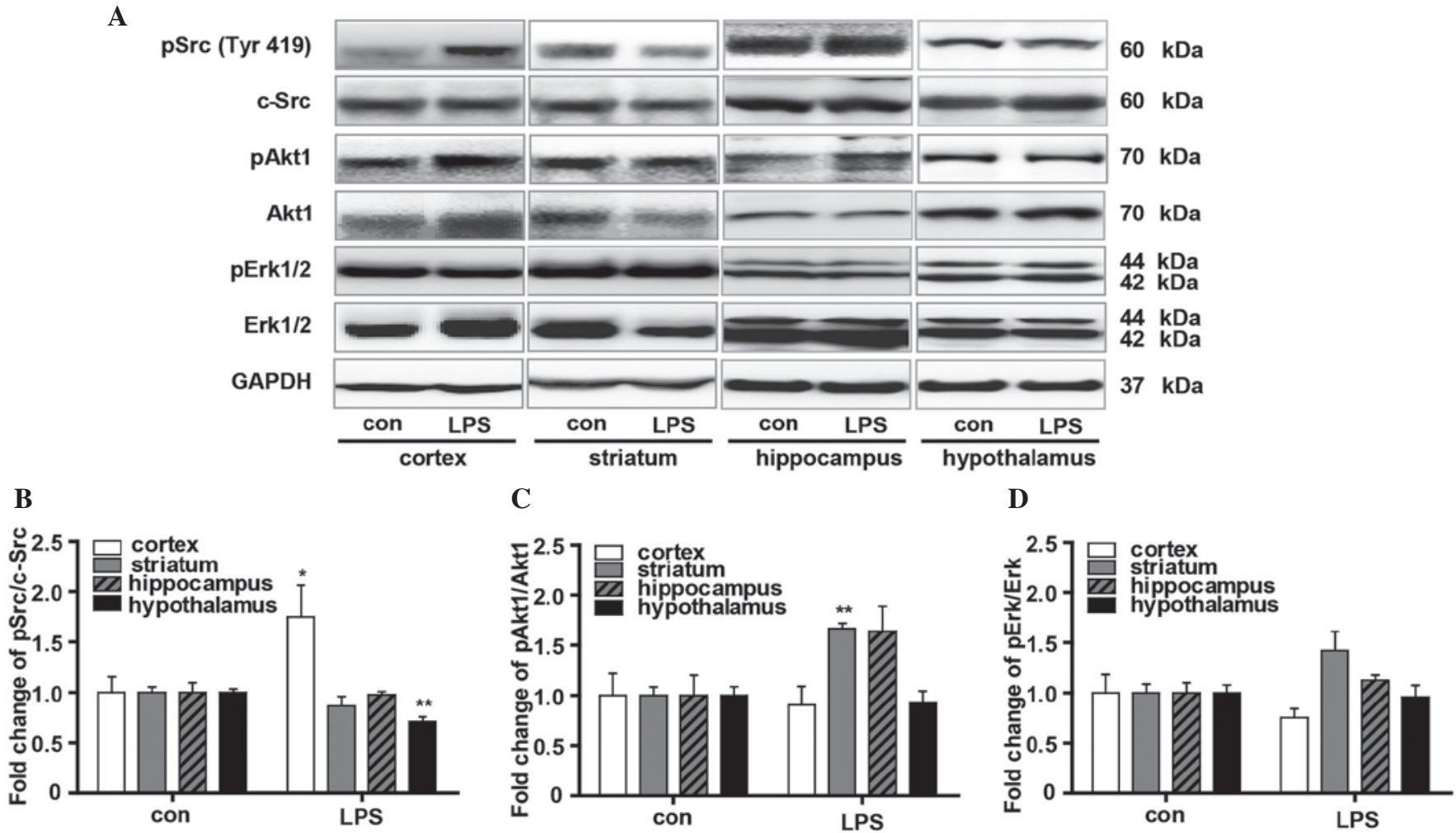

Figure 4. Evaluation of the effects of LPS on the signaling pathway downstream of Nrg1. (A) Western blot analysis of the effect of LPS on the phosphorylation of Src, Akt1 and Erk in the cortex, striatum, hippocampus and hypothalamus in mice. Graphs presenting quantification of (B) Src, (C) Akt1 and (D) Erk western blot results. Independent Student's t-test was applied. $\mathrm{P}<0.05$ and $^{* * *} \mathrm{P}<0.01$ vs. the control group (control group, $\mathrm{n}=3$; LPS group, $\mathrm{n}=4$ ). LPS, lipopolysaccharide; $\mathrm{Nrg1}$, neuregulin 1; Erk, extracellular signal-regulated kinase; p-, phosphorylated; GAPDH, glyceraldehyde 3-phosphate dehydrogenase.

nitric oxide synthase, nitric oxide, cyclooxygenase-2, and prostaglandin $\mathrm{E}_{2}$ (24). A loss of ADAM17-mediated growth factor shedding was reported to abrogate cytokine release of primary SMC stimulated by LPS or the supernatant of acid-exposed epithelial cells (23). Previous studies have revealed that Nrg1 functions by blocking the delayed neuronal death and proinflammatory responses in rats subjected to focal ischemic stroke (25). Neuregulins can modulate a diverse array of biological effects based on the expression of the receptors and cell types that are associated with the survival and function of neuronal cells (26-30). To the best of our knowledge, the present study observed for the first time the differential changes in Nrg1 expression and the phosphorylation of its receptors Neu and ErbB4, as well as of its downstream signaling molecules, in different brain regions of the mouse following neuroinflammation induced by LPS. Either type I or type II Nrg1 mRNA levels were reduced by LPS in the hippocampus, striatum and hypothalamus, whereas the mRNA level of its receptor Neu was reduced only in the hypothalamus. Using western blotting, it was demonstrated that the expression of several isoforms of $\mathrm{Nrg} 1$ was upregulated in the cortex and hippocampus in response to LPS. However, their expression was downregulated in the LPS-affected striatum and hypothalamus, in which the phosphorylation levels of Neu and ErbB4 were notably downregulated. These combined results suggest that LPS can differentially modulate the expression of $\mathrm{Nrg} 1$ signaling, and that $\mathrm{Nrg} 1$ may differentially function in different brain regions upon neuroinflammation.

Inflammation is considered to activate transcription factors, including nuclear factor (NF)-кB and Jak-STAT, which can regulate pro-inflammatory gene expression. $\mathrm{Nrg} 1$ and its receptors ErbB3 and ErbB4 are highly expressed not only in the developing nervous system but also in the mature nervous system (31-33). Following brain lesion development, the levels of Nrg and the ErbB4 receptor are increased $(34,35)$, suggesting that $\mathrm{Nrg} / \mathrm{ErbB} 4$ signaling may function in synaptic plasticity and neuroprotection. $\mathrm{Nrg} 1$ is crucial in the development of the brain (36), laying the foundation for its roles in inflammation-related processes in the disease setting. It is considered that $\mathrm{Nrg} 1$ functions upstream of NF- $\mathrm{kB}$-mediated cell signaling in response to certain inflammatory conditions (37).

The mechanisms underlying the role of Nrg1 in neuroinflammation are unknown. It has been reported that $\mathrm{Nrg} 1 \beta$ can exert neuroprotective effects on cell survival via the activation of the phosphatidyl-inositol-3-kinase (PI3K)/Akt signaling pathway $(38,39)$. It was suggested that the potential neuroprotective effects of $\mathrm{Nrg} 1$ are due to its ability to modulate multiple biological processes during neuroinflammation. To test this, Nrg1 and the phosphorylation levels of certain signaling pathway proteins, including Src, Aktl and Erk were examined. Using western blotting techniques, it was demonstrated that the phosphorylation level of Src was increased in the cortex but decreased in the hypothalamus. However, the phosphorylation levels of Akt1 and Erk were upregulated in the striatum and hippocampus.

In conclusion, the present results show differential changes in $\mathrm{Nrg} 1$ signaling in major mouse brain regions in response to LPS, suggesting a differential role for $\mathrm{Nrg} 1$ in these brain regions during the development of neuroinflammation. Modulating 
Nrg1 signaling may assist in the treatment of neurotraumatic and neurodegenerative diseases that involve neuroinflammation.

\section{Acknowledgements}

The authors would like to thank the National Natural Science Foundation of China (grant nos. 81171138 and 81471279 to Dr Wei-Jiang Zhao). This study was also supported by the Talent Support Grant from SUMC (grant no. 2501220118 to Dr Wei-Jiang Zhao).

\section{References}

1. Woo RS, Li XM, Tao Y, Carpenter-Hyland E, Huang YZ, Weber J, Neiswender H, Dong XP, Wu J, Gassmann M, et al Neuregulin-1 enhances depolarization-induced GABA release. Neuron 54: 599-610, 2007.

2. Hancock ML, Canetta SE, Role LW and Talmage DA: Presynaptic type III neuregulin1-ErbB signaling targets alpha7 nicotinic acetylcholine receptors to axons. J Gen Physiol 131: i4, 2008

3. Liu J and Kern JA: Neuregulin-1 activates the JAK-STAT pathway and regulates lung epithelial cell proliferation. Am J Respir Cell Mol Biol 27: 306-313, 2002.

4. Shamir A and Buonanno A: Molecular and cellular characterization of Neuregulin-1 type IV isoforms. J Neurochem 113: 1163-1176, 2010.

5. Shyu WC, Lin SZ, Chiang MF, Yang HI, Thajeb P and Li H: Neuregulin-1 reduces ischemia-induced brain damage in rats. Neurobiol Aging 25: 935-944, 2004

6. Zhao W and Ren SG: Neuregulin-1 (Nrg1) is mainly expressed in rat pituitary gonadotroph cells and possibly regulates prolactin (PRL) secretion in a juxtacrine manner. J Neuroendocrinol 23 : 1252-1262, 2011

7. Zhao W, Shen Y and Ren S: Endogenous expression of Neuregulin-1 (Nrg1) as a potential modulator of prolactin (PRL) secretion in GH3 cells. Cell Tissue Res 344: 313-320, 2011.

8. Zhao WJ and Ren SG: Endogenous neuregulin-1 expression in the anterior pituitary of female Wistar-Furth rats during the estrous cycle. Nan Fang Yi Ke Da Xue Xue Bao 31: 921-927, 2011 (In Chinese).

9. Peles E, Ben-Levy R, Tzahar E, Liu N, Wen D and Yarden Y: Cell-type specific interaction of Neu differentiation factor (NDF/heregulin) with Neu/HER-2 suggests complex ligand-receptor relationships. EMBO J 12: 961-971, 1993.

10. Puricelli L, Proietti CJ, Labriola L, Salatino M, Balañá ME Aguirre Ghiso J, Lupu R, Pignataro OP, Charreau EH, Bal de Kier Joffé E and Elizalde PV: Heregulin inhibits proliferation via ERKs and phosphatidyl-inositol 3-kinase activation but regulates urokinase plasminogen activator independently of these pathways in metastatic mammary tumor cells. Int J Cancer 100: 642-653, 2002.

11. Rebola N, Simões AP, Canas PM, Tomó AR, Andrade GM, Barry CE, Agostinho PM, Lynch MA and Cunha RA: Adenosine A2A receptors control neuroinflammation and consequent hippocampal neuronal dysfunction. J Neurochem 117: 100-111, 2011.

12. Chaudhury AR, Gerecke KM, Wyss JM, Morgan DG, Gordon MN and Carroll SL: Neuregulin-1 and erbB4 immunoreactivity is associated with neuritic plaques in Alzheimer disease brain and in a transgenic model of Alzheimer disease. J Neuropathol Exp Neurol 62: 42-54, 2003

13. Viehover A, Miller RH, Park SK, Fischbach G and Vartanian T: Neuregulin: An oligodendrocyte growth factor absent in active multiple sclerosis lesions. Dev Neurosci 23: 377-386, 2001.

14. Corfas G, Roy K and Buxbaum JD: Neuregulin 1-erbB signaling and the molecular/cellular basis of schizophrenia. Nat Neurosci 7: 575-580, 2004

15. Ritch PA, Carroll SL and Sontheimer H: Neuregulin-1 enhances motility and migration of human astrocytic glioma cells. J Biol Chem 278: 20971-20978, 2003

16. Hirsch EC and Hunot S: Neuroinflammation in Parkinson's disease: A target for neuroprotection? Lancet Neurol 8: 382-397, 2009.

17. Gaillard PJ, de Boer AB and Breimer DD: Pharmacological investigations on lipopolysaccharide-induced permeability changes in the blood-brain barrier in vitro. Microvasc Res 65: 24-31, 2003.
18. Glezer I, Simard AR and Rivest S: Neuroprotective role of the innate immune system by microglia. Neuroscience 147: 867-883, 2007.

19. Nawa $\mathrm{H}$ and Takei $\mathrm{N}$ : Recent progress in animal modeling of immune inflammatory processes in schizophrenia: Implication of specific cytokines. Neurosci Res 56: 2-13, 2006.

20. Hoffmann I, Bueter W, Zscheppang K, Brinkhaus MJ, Liese A, Riemke S, Dörk T, Dammann O and Dammann CE: Neuregulin-1, the fetal endothelium, and brain damage in preterm newborns. Brain Behav Immun 24: 784-791, 2010.

21. Cao M, Zheng H, Tan X, Xu W, Rui Y, Li L, Liu X, Xu G, Cui G, $\mathrm{Xu}$ J, et al: Upregulation of CBLL1 in rat brain cortex after lipopolysaccharide treated. J Mol Histol 44: 135-145, 2013.

22. Chiu K, Lau WM,Lau HT, So KF and Chang RC: Micro-dissection of rat brain for RNA or protein extraction from specific brain region. J Vis Exp: 269, 2007.

23. Dreymueller D, Martin C, Schumacher J, Groth E, Boehm JK, Reiss LK, Uhlig S and Ludwig A: Smooth muscle cells relay acute pulmonary inflammation via distinct ADAM17/ErbB axes. J Immunol 192: 722-731, 2014.

24. Zhu L, Bi W, Lu D, Zhang C, Shu X, Wang H, Qi R, Shi Q and $\mathrm{Lu} \mathrm{D}$ : Regulation of ubiquitin-specific processing protease 8 suppresses neuroinflammation. Mol Cell Neurosci 64: 74-83, 2015.

25. Xu Z, Jiang J, Ford G and Ford BD: Neuregulin-1 is neuroprotective and attenuates inflammatory responses induced by ischemic stroke. Biochem Biophys Res Commun 322: 440-446, 2004.

26. Bermingham-McDonogh O, McCabe KL and Reh TA: Effects of GGF/neuregulins on neuronal survival and neurite outgrowth correlate with erbB2/neu expression in developing rat retina. Development 122: 1427-1438, 1996.

27. Verdi JM, Groves AK, Farinas I, Jones K, Marchionni MA, Reichardt LF and Anderson DJ: A reciprocal cell-cell interaction mediated by NT-3 and neuregulins controls the early survival and development of sympathetic neuroblasts. Neuron 16: 515-527, 1996.

28. Vaskovsky A, Lupowitz Z, Erlich S and Pinkas-Kramarski R: ErbB-4 activation promotes neurite outgrowth in PC12 cells. J Neurochem 74: 979-987, 2000.

29. Erlich S, Goldshmit Y, Lupowitz Z and Pinkas-Kramarski R: ErbB-4 activation inhibits apoptosis in PC12 cells Neuroscience 107: 353-362, 2001.

30. Goldshmit Y, Erlich S and Pinkas-Kramarski R: Neuregulin rescues PC12-ErbB4 cells from cell death induced by $\mathrm{H}_{2} \mathrm{O}_{2}$. Regulation of reactive oxygen species levels by phosphatidylinositol 3-kinase. J Biol Chem 276: 46379-46385, 2001.

31. Marchionni MA, Goodearl AD, Chen MS Bermingham-McDonogh O, Kirk C, Hendricks M, Danehy F, Misumi D, Sudhalter J, Kobayashi K, et al: Glial growth factors are alternatively spliced erbB2 ligands expressed in the nervous system. Nature 362: 312-318, 1993.

32. Pinkas-Kramarski R, Eilam R, Spiegler O, Lavi S, Liu N, Chang D, Wen D, Schwartz M and Yarden Y: Brain neurons and glial cells express Neu differentiation factor/heregulin: A survival factor for astrocytes. Proc Natl Acad Sci USA 91: 9387-9391, 1994.

33. Pinkas-Kramarski R, Eilam R, Alroy I, Levkowitz G, Lonai P and Yarden Y: Differential expression of NDF/neuregulin receptors ErbB-3 and ErbB-4 and involvement in inhibition of neuronal differentiation. Oncogene 15: 2803-2815, 1997.

34. Eilam R, Pinkas-Kramarski R, Ratzkin BJ, Segal M and Yarden Y: Activity-dependent regulation of Neu differentiation factor/neuregulin expression in rat brain. Proc Natl Acad Sci USA 95: 1888-1893, 1998.

35. Erlich S, Shohami E and Pinkas-Kramarski R: Closed head injury induces up-regulation of ErbB-4 receptor at the site of injury. Mol Cell Neurosci 16: 597-608, 2000.

36. Esper RM, Pankonin MS and Loeb JA: Neuregulins: Versatile grow th and differentiation factors in nervous system development and human disease. Brain Res Rev 51: 161-175, 2006.

37. Ghosh S, May MJ and Kopp EB: NF-kappa B and Rel proteins Evolutionarily conserved mediators of immune responses. Annu Rev Immunol 16: 225-260, 1998.

38. Buonanno A and Fischbach GD: Neuregulin and ErbB receptor signaling pathways in the nervous system. Curr Opin Neurobiol 11: 287-296, 2001

39. Li BS, Ma W, Jaffe H, Zheng Y, Takahashi S, Zhang L, Kulkarni AB and Pant HC: Cyclin-dependent kinase- 5 is involved in neuregulin-dependent activation of phosphatidylinositol 3-kinase and Akt activity mediating neuronal survival. J Biol Chem 278: 35702-35709, 2003. 